\title{
Registro de Iynxacariose em Felis catus domesticus na cidade de Jundiaí, Estado de São Paulo
}

\section{Occurrence of lynxacariose in Felis catus domesticus in Jundiaí city, State of São Paulo}

\author{
Leila Maria Silva Lopes ${ }^{1}$, Ana Cristina de Castro Lopes², Nicolau Maués Serra-Freire ${ }^{3}$
}

\begin{abstract}
Resumo
Ácaros parasitas de pêlos de felino examinado na cidade de Jundiaí, Estado de São Paulo, foram identificados no Laboratório de Morfofisiologia e Patogenia de Carrapatos (LMPC) da Universidade Federal Rural do Rio de Janeiro (UFRRJ) como a espécie Lynxacarus radovskyi, constituindo o primeiro registro desta espécie de parasito no Estado de São Paulo.
\end{abstract}

Palavras chave: ácaros; Listrophoridae; Lynxacarus radovskyi; felinos

O Lynxacarus radovskyi Tenório, 1974 é um ácaro sarcoptiforme da família Listrophoridae. Esta espécie foi inicialmente descrita no Havaí, quando foi observada a presença de uma placa propodossomal unida ao gnatossoma apenas por um istmo fortemente quitinizado; foram, também, assinaladas características morfofisiológicas diferenciais para outras espécies da mesma família (Tenório, 1974). Houve inclusive o cuidado de considerar os ácaros do gênero Listrophorus para enfatizar os caractéres idênticos e os diferenciais aos da espécie L. radovskyi.

Em Porto Rico, foi apontada a presença em gato doméstico, com proposição de recombinação para o gênero Felistrophorus (Fox, 1977). Tal proposição não foi considerada quando foi notificada a ocorrência em gatos domésticos de pelagem branca na Austrália (Bowman, 1978), em Fiji (Munro e Munro, 1979) e no Brasil (Alves et al., 1993).

Munro e Munro (1979) observaram altas concentrações desse ácaro na pele que delimita a base do pêlo em gatos de Fiji. Os hospedeiros apresentavam marcada alopécia e reação inflamatória decorrente do processo de automutilação conseqüente de prurido intenso; esses autores concluíram que um número reduzido de parasitos é suficiente para determinar prurido em função do elevado grau de espoliação. Tảmbém salientaram o risco iminente de reinfestação apesar do trataménto. Na Flórida, Greve e Gerrish (1981) consideraram os dois gêneros como sinônimos, prevalecendo o Felistrophorus radovskyi, quando registraram a primeira ocorrência do parasito em felinos nos EUA.

O material preservado seco foi recebido pelo LMPC/ UFRRJ, correspondendo à fração aproximada de 450 pêlos provenientes de raspagem da pele de um felino de pelagem branca que fora examinado na Clínica Veterinária Anchieta, em dezembro de 1994, na cidade de Jundiaí, Estado de São Paulo. O animal apresentava histórico de alopécia e prurido na base da cauda e região perianal. No LMPC uma fração do material foi examinada com auxílio de estereomicroscópio com aumento de até $400 x$ e foi constatada a presença de ectoparasitos fixados aos pêlos. Os ácaros foram retirados dos pêlos e submetidos à técnica de clarificação, fixação e montagem de lâminas permanentes com bálsamo do Canadá; técnica idêntica à publicada por Amorim e Serra-Freire (1995). A outra fracão do material foi trabalhada por metalização com ouro em pó para exame por microscopia eletrônica de varredura. O restante do material, registro $n^{\circ}=229 / L M P C$, foi depositado na Coleção Acarológica do Instituto Oswaldo Cruz sob o no LIS-001.

Constatou-se que os parasitos eram machos, fêmeas e ninfas de ácaros Astigmatas apresentando características morfológicas compatíveis com o proposto por Tenório (1974); foram, assim, identificados como L. radovskyi(Fig.) e foi registrada, a primeira ocorrência desta espécie no Estado de São Paulo.

\section{Agradecimentos}

A Médica Veterinária Laura Celi de Souza Silva, Clínica Veterinária Anchieta, Jundiaí, Estado de São Paulo.

\footnotetext{
1 Aluna de Doutorado do CPGMV-PV-LMPC/UFRRJ

2 Acadêmica de Medicina-Veterinária-Estagiária LMPC/UFRRJ 3 Departamento de Parasitologia Veterinária, CPGMV, PV-LMPC, Universidade Federal Rural do Rio de Janeiro (UFRRJ), Km 47 Antiga Rodovia
Rio-São Paulo, 23851-970 Seropédica,RJ, Brasil
} 


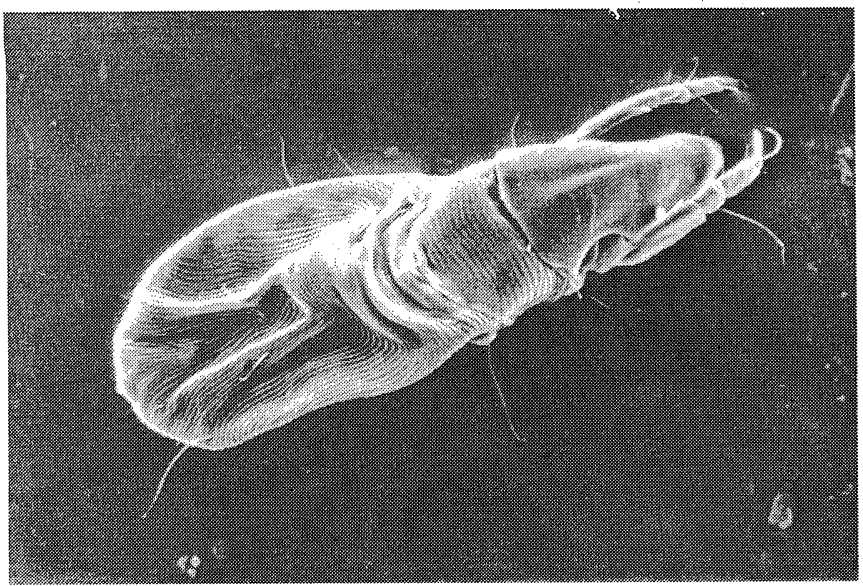

Lynxacarus radovsky, ninfa; eletromicrografia em microscopia eletrônica de varredura, $400 \mathrm{x}$.

\section{Abstract}

Occurrence of lynxacariose in Felix catus domesticus in Jundiaí city, State of São Paulo

Mites from a cat fur examined in Jundiaí city, State of São Paulo, were identified at Tick Morfofisiology and Pathogeny Laboratory (UFRRJ) as Lynxacarus radovskyi.
This is the first occurrence of the species registred in southeastern Brazil.

Key words: mites; Listrophoridae; Lynxacarus radovskyi; felione

\section{Referências bibliográficas}

Alves LC, Ramos QFCC, Pereira IHO 1993. Ocorrência de Lynxacariose em felinos na cidade de Recife. Revta Brasil Parasitol 2(2) Supl. 1: 10.

Amorim M, Serra-Freire NM 1995. Descrição morfológica do estádio de larva de carrapato (Acari:Ixodidae). 1. Amblyomma rotundatum, Kock, 1844. Parasitologia ao Dia 19(1-2): 9-19.

Bowman WL 1978. The cat fur-mite (Lynxacarus radovskyi) in Autralia. Australian Vet J 54: 403-404.

Fox I 1977. Felistrophorus, a new genus of mites on cats in Puerto Rico (Acarina: Listrophoridae). Proc Entomol Soc Washington 79(2): 242-244.

Greve JH, Gerrish RR 1981. Fur mites (Lynxacarus) from cats in Florida. Feline Practice 11(6): 28-30.

Munro R, Munro HMC 1979. Lynxacarus on cats in Fiji. Australian Vet J 55: 90.

Tenório JM 1974. A new species of Lynxacarus (Acarina: Astigmata: Listrophoridae) from Felis catus in the Hawaiian Islands. J M Entomol 11: 599-604. 